\title{
XLV. On the contact potential differences determined by means of null solutions
}

\section{S.W.J. Smith M.A. \& H. Moss B.Sc.}

To cite this article: S.W.J. Smith M.A. \& H. Moss B.Sc. (1908) XLV. On the contact potential differences determined by means of null solutions, Philosophical Magazine Series 6, 15:88, 478-497, DOI: $10.1080 / 14786440809463790$

To link to this article: http://dx.doi.org/10.1080/14786440809463790

册 Published online: 16 Apr 2009.

Submit your article to this journal $\lceil\pi$

Џ Article views: 3

Q View related articles $\asymp$ 
XLV. On the Contact Potential Differences determined by means of Null Solutions. By S. W. J. SMIrH, M.A., and H. Moss, B.Se., Royal College of Science, London*.

$\$$ 1. Introduction.

4. Palmaer's "null solutions."

7. A method of search for other null solutions.

$\$ 9$. Null solution of $\mathrm{KCN}$.

12. Effect of $\mathrm{Na}_{2} \mathrm{~S}$ upon the p.d. between $\mathrm{Hg}$ and $\mathrm{KCl}$.

16. Null solution of $\mathrm{KCl}$.

17. Effect of oxygen upon Paschen's relation.

$\S 18$. Inferences from results obtained with null solutions of $\mathrm{KCN}$ and of $\mathrm{KCl}$.

$\S 19$. Null solution of KI.

$\$ 20$. Null solution of $\mathrm{KOH}$.

$\S 21$. Summary of conclusions.

1. TNTRODUCTION.-The processes which occur during the polarization of electrodes are of considerable theoretical and practical importance. Being largely surface effects, they can be followed, in the case of mercury, by observation of the changes of the surface-tension which result from polarization. Mercury electrodes have been the subject of much study in this way, but while the interpretation of some of the results seems clear, there are others which have been the subject of frequent discussion. Chief amongst these is the significance of the maximum surface-tension between mercury and the electrolyte which occurs at some particular degree of polarization in almost every solution that has been examined. The maximum was for long supposed to indicate zero potential-difference between the mercury and the solttion; but the adequacy of this hypothesis, as a general interpretation of the significance of the maximum, is now very doubtful.

$\$ 2$. Evidence was given by one of us (Phil. Trans. A. $1899, \mathrm{pp} .47-87)$, in discussing the validity of the LippmannHelmholtz theory of electrocapillarity, that the maximum surface-tension between mercury and certain electrolytes is not reached when the potential-difference is zero. İt was shown that, for equally concentrated solutions of the particular electrolytes $\mathrm{KCl}$ and $\mathrm{KI}$, the potential-differences at the respective maxima differ to such an extent that if one is assumed to be zero the other must be nearly a quarter of a volt (l.c. pp. 70, 71). The assumption of zero potentialdifference in either case is arbitrary. It is possible that the potential-difference at the maximum surface-tension is zero. in some electrolytes; but the evidence from the electro-

* Communicated by the Physical Society ; read February 28, 1908. 
capillary curves (l. c. pp. $68 \& 82$ ), while not conclusive, favours the view that it is not so in any of the moderately dilute solutions of $\mathrm{KCl}$ and $\mathrm{KI}$ (giving "depressed" maxima) referred to above.

Palmaer has, however, published experiments recently from which it would seem that in the case of $n / 10 \mathrm{KCl}$, the potential-difference at the maximum surface-tension is, if not zero, at least very small. This result, if conclusive, would be of great theoretical value, and we have therefore performed the experiments described below to test the validity of Palmaer's deductions.

§3. Palmaer published in 1903 (Zeitsch. f. Elektrochemie, ix. pp. 754-757) a summary of certain experiments with drop electrodes, by means of which he sought to show that the true contact potential-difference between mercury and $n / 10 \mathrm{KCl}$ solution is about 0.57 volt, and he has quite recently (Zeitsch. f. physik. Chemie, lix. pp. 129-191, 1907) given a full account of these experiments and of others, from which his final conclusion is that the potential-difference in question is $0.5732+.0003$ volt at $18^{\circ} \mathrm{C}$.

One of us found that the maximum surface-tension between mercury and $n / 10 \mathrm{KCl}$ solution was produced by a polarizing electromotive force of $0.568 \pm \cdot 01$ volt $(l . c . p .71)$. It would thus appear that, after all, in the case of $n / 10 \mathrm{KCl}$, the potential-difference at the maximum surface-tension is practically zero, for it is represented by the difference between the two numbers just given. We shall attempt to show however that, although of much interest in connexion with electrocapillarity, Palmaer's deduction from his experiments is not necessarily true, and that his results leave the knowledge of the contact potential-difference between $\mathrm{Hg}$ and $n / 10 \mathrm{KCl}$ substantially in the same state of uncertainty as before.

$\S 4$. Palmaer's Null Solutions.-When certain conditions, first fully discussed by Paschen, are fulfilled, a mercury electrode immersed in $n / 10 \mathrm{KCl}$ shows a potential about 0.57 volt higher than that of an electrode of mercury streaming into the same solution. Palmaer found that by adding certain substances to this $n / 10 \mathrm{KCl}$ solution, he could not only reduce the observed potential-difference between the still and dropping mercury until it became very small, but could cause it, passing through the value zero, to change in sign. In this way. he found two different "null solutions," one containing small quantities of $\mathrm{KCN}, \mathrm{KOH}$, and $\mathrm{Hg}(\mathrm{CN})_{2}$, and $2 \mathrm{~K} 2$ 
the other $\mathrm{H}_{2} \mathrm{~S}$ and a small quantity of acetic acid, for which the potential-difference between the still and dropping electrodes was zero. It is of course well known that a concentrated solution of a mercury salt behaves like a Palmaer null solution in the respect that there is practically no p.d. between still and dropping mercury electrodes immersed in it; but small variations in the composition do not here produce effects of the kind observed by Palmaer. Moreover, the absence of a p.d. in this case has been explained in a way which is not applicable when the amount of dissolved mercury is very small.

$\S 5$. Experiments of the kind performed by Palmaer were suggested by Nernst (Ann. d. Physik, lviii. p. 11, 1896), and it is obvious that the results can be explained, either according to the Helmholtz theory of dropping-electrodes or to that of Nernst, if we assume that when the observed E.M.F. is zero a solution has been found which exhibits no potentialdifference with respect to mercury. In such a case there would be no tendency to produce an E.M.F., whether, in the general case, the double-layer potential is altered by extension of the mercury surface (Helmholtz), or whether the doublelayer forms practically instantaneously but is accompanied by concentration changes in the solution (Nernst).

$\$ 6$. Connecting each of his null solutions in turn to a solution of $\dot{n} / 10 \mathrm{KCl}$, Palmaer measured the p.d. between mercury in the null solution and mercury in the $n / 10 \mathrm{KCl}$. Allowing for small contact potential-differences between the electrolytes, he found practically identical values (of which the mean is the number already quoted) for the p.d. $\mathrm{Hg} \mid n / 10 \mathrm{KCl}$. Strictly, these measurements prove only that the p.d. between mercury and each of the null solutions was the same.

Palmaer found only two satisfactory null solutions; but experiments with several others are described below. From these experiments it will be seen that the p.d. between mercury and a null solution of the type described by Palmaer is not always the same, and hence is never necessarily zero as Palmaer assumes.

§ 7. A method of search for other Null Solutions.-In searching for other null solutions we were guided by the relation deducible from Paschen's experiments, that although the p.d. between $\mathrm{Hg}$ and an electrolyte when the surfacetension is a maximum need not be zero, it is nevertheless always equal to the p.d. between a dropping electrode of the 
Potential Differences determined by Null Solutions. 481 .

Paschen type (Wied. Ann.xli. p. 42, 1890) and the same electrolyte (cf. Phil. Trans. l. c. pp. 83 et seq.). We have found, in the course of the present experiments, that the statement of this relation, which is one of the most important in electrocapillarity, requires qualification. The relation is true only when the medium through which the mercury falls before it enters the solution does not contain a constituent which interacts chemically with the mercury and the solution. In some cases, for example, the relation does not hold until the air surrounding the dropping electrode and the solution is replaced by hydrogen, nitrogen, or other non-oxidising medium.

\$ 8. Assuming the truth of the above relation, it was. obvious that any solution for which the maximum of the electrocapillary curve lay at the origin (applied E.M.F. zero) would be a null solution. If the maximum for a given solution were slightly $(a)$ to the right or $(b)$ to the left of the origin, then the still electrode for that solution would be slightly $(a)$ positive or $(b)$ negative to the dropping electrode. The change in sign of the potential of the dropper with respect to the still electrode, with a small change in the composition of the electrolyte, would not correspond necessarily (as assumed by Palmaer) with a change in the sign of the potential of the still mercury with respect to the solution, but only with a change from one side of the origin to the other of the maximum of the electrocapillary curve.

Since it is almost certain that this maximum does not always correspond with zero potential-difference, it seemed equally certain that a null solution of the kind studied by Palmaer could not always, and need not ever, be one exhibiting no contact p.d. with respect to mercury.

§ 9. Null Solution of KCN.-It has long been known that moderately concentrated solutions of KCN give electrocapillary curves of which the maxima lie to the left of the origin (applied E.M.F. negative), while weaker solutions give curves of which the maxima lie to the right. If a solution could be found of which the maximum lay at the origin, this would be a null solution of the kind studied by Palmaer. A null solution of KCN was apparently found approximately by Amelung in a rasearch which Palmaer describes (Zeits. f. physik. Chemie, lix. p. 164, 1907) but regards as unsatisfactory. This solution used according to Palmaer's method would give a value of roughly 0.7 volt for the contact potential $\mathrm{Hg} \mid n / 10 \mathrm{KCl}$. It was obtained by 
gradual dilution of a saturated solution of $\mathrm{KCN}$ until the p.d. between the drop electrode and the still electrode became zero.

We have found and examined a null KCN solution in another way. A normal solution of $\mathrm{KCN}$ was made up and this, together with weaker solutions of definite strength, obtained from it by dilution, was then examined as described below. As it was found that the electrocapillary properties of solutions, apparently of equal concentration, produced from different samples of $\mathrm{KCN}$ frequently differed considerably, the precise constitutions of the different solutions cannot be specified. This, however, is of no importance to the validity of the experiments. For the sample of KCN used in the experiments, the null solution contained about $0.26 n \mathrm{KCN}$; but another sample from another source would probably have given a different result.

The following quantities were observed in the case of each solution :-

1. The electrocapillary curve-the reading for maximum surface-tension, and the E.M.F. required to produce it, being noted as carefully as possible.

2. The electrocapillary curve of a solution of $\mathrm{KCl}$ of equal strength.

3. The horizontal distance between the descending branches of the two curves ( $f f$. Phil. Trans. l. c. p. 69).

4. The E.M.F. of the cell $\mathrm{Hg}|\mathrm{KCN} \vdots \mathrm{KCl}| \mathrm{Hg}$.

5. The E.M.F. of the dropping electrode circuit $\mathrm{Hg}|\mathrm{KCN}| \mathrm{Hg}$, the measurements being taken when the end of the continuous part of the jet was in the surface of the solution (Paschen).

6. The E.M.F. of the dropping electrode circuit $\left.\mathrm{Hg}\right|_{\downarrow} \mathrm{KCN} \vdots \mathrm{KCl} \mid \mathrm{Hg}$.

Some of the electrocapillary curves are shown in fig. 1, the others being omitted to avoid confusion. The KCN curves are very flat near the maxima, and the E.M.F.s corresponding to these maxima are relatively difficult to determine. 
Potential Differences determined by Null Solutions. 483

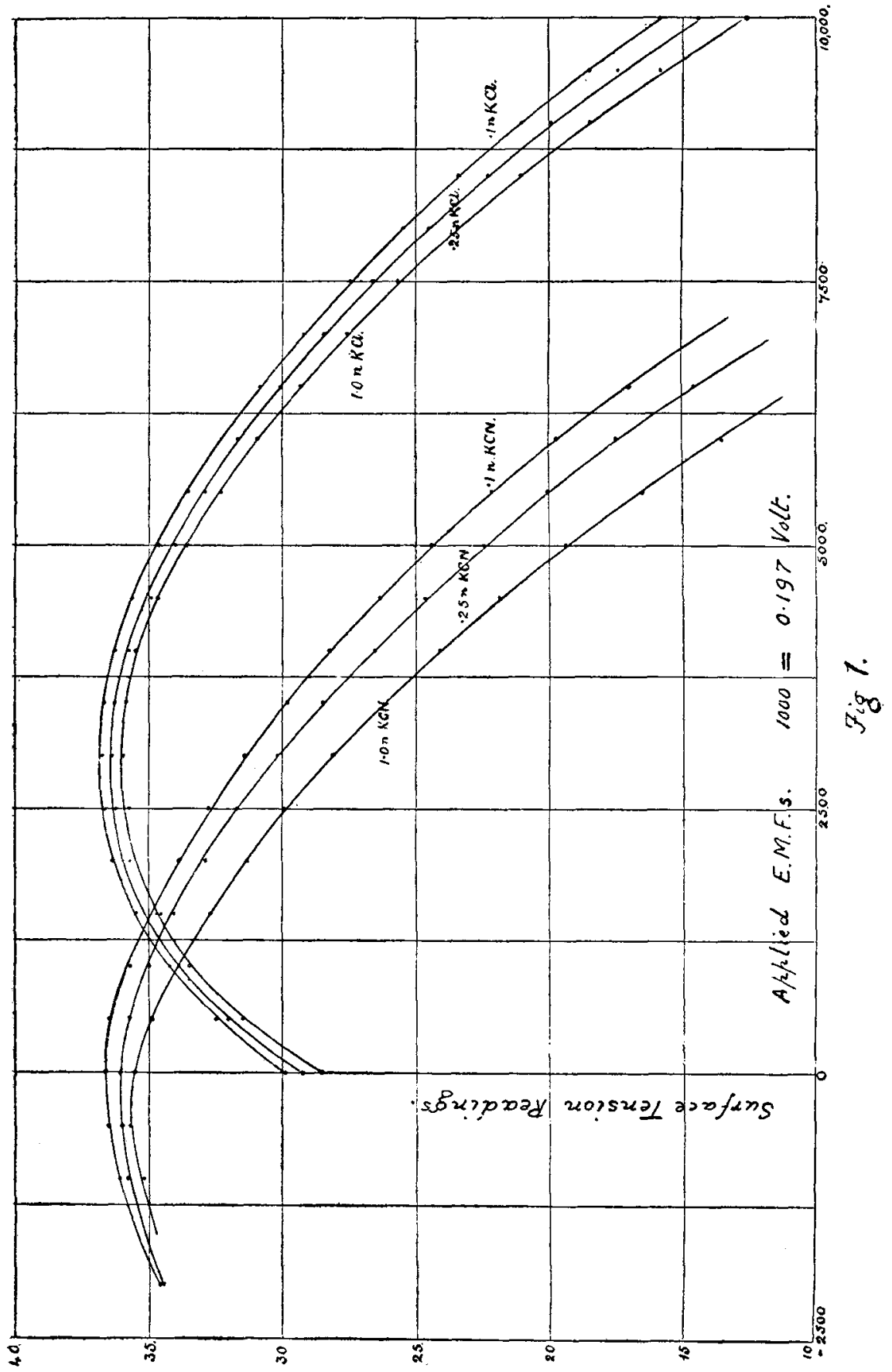


The chief results of the measurements are summarized in the following Table :-

\begin{tabular}{|c|c|c|c|c|c|c|c|}
\hline & I. & 2. & 3. & 4. & 5. & 6. & 7. \\
\hline $\begin{array}{l}\text { Strengths } \\
\text { of } \\
\text { solutions. }\end{array}$ & $\begin{array}{c}\text { Max. S.T. } \\
\text { KCN } \\
\text { (scale- } \\
\text { reading). }\end{array}$ & $\begin{array}{c}\text { Max. S.T. } \\
\text { KCl } \\
\text { (scale- } \\
\text { reading). }\end{array}$ & $\begin{array}{c}\text { E.M.F.of } \\
\text { Max.S.T. } \\
\text { KCX } \\
\text { volt. }\end{array}$ & $\begin{array}{c}\text { Horizontal } \\
\text { distance } \\
\text { between } \\
\text { curves. } \\
\text { volt. }\end{array}$ & $\begin{array}{c}\mathrm{KCN}: \mathrm{KCl}+ \\
\text { volt. }\end{array}$ & $\underset{\text { volt. }}{\mathrm{KCN}}+$ & $\mid \begin{array}{c}\mathbf{K O N} \\
\text { rolt. }\end{array}$ \\
\hline $0 \cdot 1 \mathrm{n}$. & $36 \cdot 65$ & 3675 & .039 & 645 & $\cdot 642$ & $\cdot 043$ & 679 \\
\hline $2 n$ & $36 \cdot 30$ & 36.70 & .020 & 667 & $\cdot 671$ & .018 & .694 \\
\hline $.24 n$ & $36 \cdot 10$ & $36 \div 3$ & .010 & 687 & 687 & .012 & 698 \\
\hline $.25 n$ & 36.08 & 36.35 & 0 & $\cdot 691$ & 690 & .003 & 699 \\
\hline$\cdot 26 n$ & 36.04 & $36 \cdot 30$ & 0 & 696 & 693 & -.001 & $\cdot 697$ \\
\hline $27 n$ & 36.00 & $36 \cdot 27$ & -.005 & 697 & 696 & -.005 & 693 \\
\hline $.50 n$ & 35.81 & $36 \cdot 17$ & -020 & $\cdot 716$ & 715 & -016 & 703 \\
\hline $1.0 n$ & $35 \cdot 70$ & $36 \cdot 10$ & $-\cdot 059$ & 748 & $\cdot 745$ & $-\cdot 046$ & $\cdot 705$ \\
\hline
\end{tabular}

Solutions of $\mathrm{KCN}$ and $\mathrm{KCl}$ of equal strength being of approximately the same conductivity and degree of ionization (cf. Kohlrausch \& Holborn, Leitvermögen der Elektrolyte, pp. $145 \& 148$ ), the contact potential-difference between them will be very small, probably less than a millivolt. This is confirmed by the agreement between the numbers in Columns 4 and 5 , since the former represents the difference between $\mathrm{Hg} \mid \mathrm{KCl}$ and $\mathrm{Hg} \mid \mathrm{KCN}$ (cf. Phil. Trans. l. $c$. pp. 69 et seg.).

Each number in Column 7 should be equal to the sum of the corresponding numbers in Columns 5 and 6 . A comparison serves to indicate the limits of the uncertainty of the dropping-electrode measurements. The jet fell freely in contact with the air. By comparison of the numbers in Columns 3 and 6 it will be seen that Paschen's relation held, within the limits of errors of experiment, in every case.

The null solution was that for which the surface-tension was a maximum in the natural state (applied E.M.F. zero). Its strength was, in round numbers, $n / 4 \mathrm{KCN}$, and assuming with Palmaer that, in consequence, $\mathrm{Hg} n / 4 \mathrm{KCN}=0$, it would give, by Column $5, \mathrm{Hg} \mid n / 4 \mathrm{KCl}=0.69$ approximately.

$\S 10$. As will be seen Jater, a solution of $n / 4 \mathrm{KCl}$, examined according to either of the methods described by Palmaer, would have given a null solution from which he would have deduced the value $\mathrm{Hg} \mid n / 4 \mathrm{KCl}=0.565$ approx. 
Potential Differences determined by Null Solutions. 485

The reason of the difference of 0.125 volt between this and the value found by the $\mathrm{KCN}$ null solution is suggested by inspection of the electrocapillary curves.

The maxima for the KCN solutions are lower than those for the $\mathrm{KCl}$ solutions of corresponding strength, and the "horizontal distance" between the curves after they become parallel is approximately 0.125 volt greater than the distance between the maxima. Consequently ( $c f$. Phil. Trans. $l . c$. p. 67) the solution at the maximum surface-tension in $\mathrm{KCN}$ is 0.125 volt more positive to the mercury than it is at the maximum in $\mathrm{KCl}$.

$\S 11$. Every solution for which the maximum of the electrocapillary curve is at the origin is a null solution, but the potential-differences between mercury and different null solutions will be different if the maxima for these solutions are not the same.

If traces of other substances can be added to a $n / 4 \mathrm{KCl}$ solution in such a way as to move the maximum of the electrocapillary curve to the origin without appreciably raising or depressing it, then such a solution will be about $0 \cdot 125$ volt less positive to mercury than the null solution of $n / 4 \mathrm{KCN}$. This null solution when measured against pure $n / 4 \mathrm{KCl}$ will give an E.M.F. of 0.565 in place of the E.M.F. of 0.69 given by the $n / 4 \mathrm{KCN}$ null solution. Hence, if Palmaer's solutions were produced from $n / 10 \mathrm{KCl}$ without appreciable alteration of the maximum, the difference between his results and ours is immediately explained.

\$12. Effect of $\mathrm{Na}_{2} \mathrm{~S}$ on the p.d. between $\mathrm{Hg}$ and $\mathrm{KCl}$ - The p.d. between mercury and an electrolyte is controlled, according to the theory of Nernst, by the concentration $p$ of the mercury ions in solution. If $\pi$ is the potential rise from the solution to the mercury, then

$$
\partial \pi / \partial p=k \mathbf{T} / p, \quad \text {. . . . . }
$$

where $\mathrm{T}$ is the absolute temperature and $k$ is a constant. The rise can therefore be diminished by decreasing $p$. From Palmaer's experiments and others (e.g., Behrend, Zeits $f$. phys. Chem. xi. p. 481, 1893), it can be inferred that a large diminution of $p$ is produced by saturating a $\mathrm{KCl}$ solution in contact with mercury with $\mathrm{H}_{2} \mathrm{~S}$. We therefore thought it likely that by addition of $\mathrm{Na}_{2} \mathrm{~S}$ to the $\mathrm{KCl}$ solution it would be possible to move the electrocapillary curve to the right, $i$.e. so that the maximum approached the origin. It remained to determine by experiment the relative amount of $\mathrm{Na}_{2} \mathrm{~S}$

* An interesting method of deducing a similar equation was given by Professor J. J. Thomson in the Philosophical Magazine for 1895 . 
necessary for the purpose of reaching the origin. Electrocapillary curves were obtained with solutions containing gradually increasing proportions of $\mathrm{Na}_{2} \mathrm{~S}$. The general composition of the solutions was

$$
x(n \mathrm{KCl})+y\left(n \mathrm{Na}_{2} \mathrm{~S}, 9 \mathrm{H}_{2} \mathrm{O}\right),
$$

where $x+y=0.1$; i.e., considering the sum of the contents, the solution was always $1 / 10$ th normal, and the content in kations remained approximately constant. Curves were obtained for a number of different values of $y$. Some of the results are shown in fig. 2, in which the values of $y$ represented are as follows:-

\begin{tabular}{|c|c|c|c|c|c|c|c|c|c|c|c|c|}
\hline No. of Solution & I. & II. & III. & IV. & $\nabla$. & VI. & VII. & VIII. & IX. & $\mathbf{X}$ & XIII. & $\mathrm{XV}$ \\
\hline Value of $y$ & 0 & $\cdot 0_{3} 2$ & $0_{3} 372$ & $0_{3} 374$ & 0,377 & $\cdot 0_{22} 1$ & $\cdot 0_{2} 2$ & $\cdot 0.5$ & .01 & $\cdot 03$ & .08 & $\cdot 10$ \\
\hline
\end{tabular}

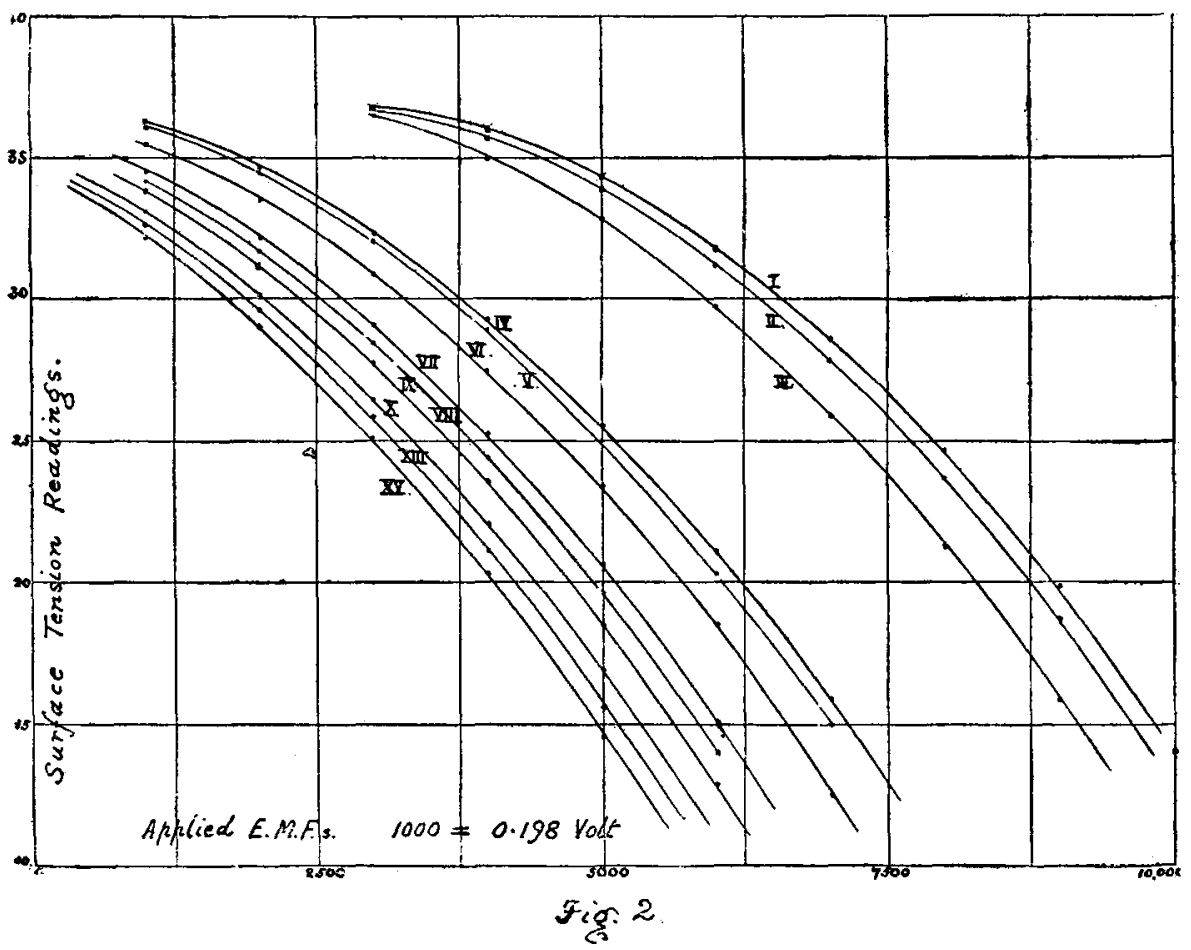

From these results it will be seen that less than ${ }^{0} 001 n \mathrm{Na}_{2} \mathrm{~S}$ added to $\cdot 099 n \mathrm{KCl}$ was sufficient to move the maximum of 
Potential Differences determined by Null Solutions. 487

the electrocapillary curve to the left of the origin. Further, when the value of $y$ was about $\cdot 00037$, an extremely small variation produced a very large change in the position of the maximum. This is represented in fig. 3, which shows how the displacement of the descending branch of the electrocapillary curve depends on the percentage composition of the $n / 10$ solution. Since the concentration in kations was the same for all solutions, this curve represents (Phil. Trans. l. c. p. 80) how the potential of the solution with respect to the mercury rises with increase in the anount of the sulphide.

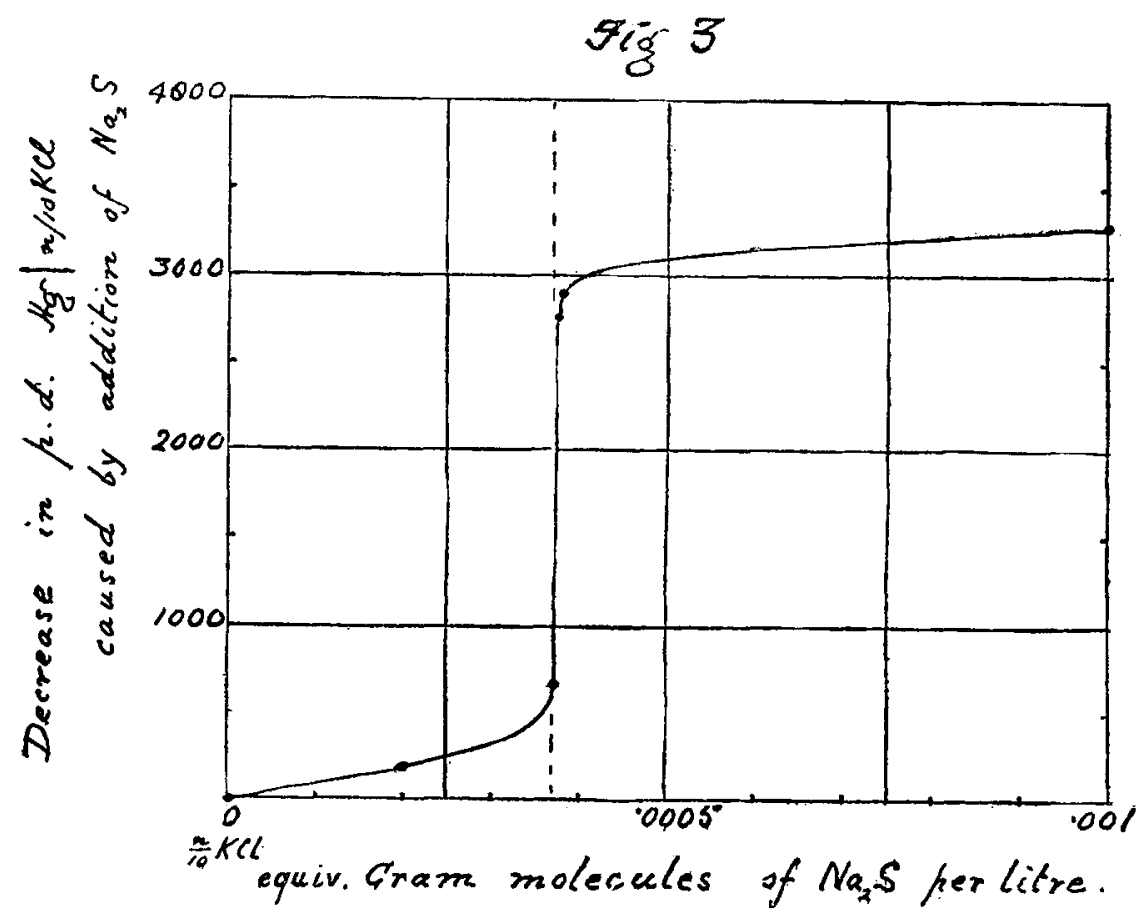

$\S 13$. The extremely rapid concentration variation of the potential near $y=\cdot 00037$ was very inconvenient for our purpose, for it happened that the solution which we sought, $i$.e. one having its electrocapillary maximum at the origin, would contain an amount of sulphide corresponding approximately to this value of $y$. The experiments of Behrend (l. c. p. 481) suggested that the rapid variation of potential at a critical value of $y$ occurred near the completion of the conversion of feebly soluble chloride of mercury into still 
less soluble sulphide. Thus, assuming $c$ to represent the concentration of $\mathrm{Hg}_{2} \mathrm{Cl}_{2}$ in solution before addition of $\mathrm{Na}_{2} \mathrm{~S}$, if the amount of sulphide added were $\left(c-c^{\prime}\right), i$. e. less than $c$, we might have (see however $\$ 15)$ :-

$$
\begin{aligned}
c \mathrm{Hg}_{2} \mathrm{Cl}_{2}+\left(c-c^{\prime}\right) \mathrm{Na}_{2} \mathrm{~S}=c^{\prime} \mathrm{Hg}_{2} \mathrm{Cl}_{2}+\left(c-c^{\prime}\right) \mathrm{Hg}_{2} \mathrm{~S} & +2\left(c-c^{\prime}\right) \mathrm{NaCl} .
\end{aligned}
$$

Assuming $\alpha$ and $\beta$ to represent the fractions of the chloride and sulphide respectively, which are electromotively active, the ionic concentration $p$ of the mercury in solution would be

$$
p=2 \alpha c^{\prime}+2 \beta\left(c-c^{\prime}\right), \text { and bence } \partial p / \partial c^{\prime}=2(\alpha-\beta) .
$$

Then, from equation (i.) above, we should have

$$
\partial \pi / \partial c^{\prime}=k \mathrm{~T}(\alpha-\beta) /\left(\alpha c^{\prime}+\beta \overline{c-\bar{c}^{\prime}}\right) .
$$

From this it is seen that if $\beta$ is very small compared with $\alpha$, the value of $\partial \pi / \partial c^{\prime}$ will become very large when $c^{\prime}$ becomes very small, $i$. $e$. when the amount of $\mathrm{Na}_{2} \mathrm{~S}$ added is very nearly equivalent to the amount of $\mathrm{Hg}_{2} \mathrm{Cl}_{2}$ in solution.

$\S 14$. When the amount of $\mathrm{Na}_{2} \mathrm{~S}$ added is in excess of the $\mathrm{Hg}_{2} \mathrm{Cl}_{2}$ in solution we may have

$$
c \mathrm{Hg}_{2} \mathrm{Cl}_{2}+\left(c+c^{\prime}\right) \mathrm{Na}_{2} \mathrm{~S}=c \mathrm{Hg}_{2} \mathrm{~S}+c^{\prime} \mathrm{Na}_{2} \mathrm{~S}+2 c \mathrm{NaCl} \text {. }
$$

From this it is seen that the potential of the liquid with respect to the electrode will continue to rise when, after the whole of the chloride is decomposed, more and more $\mathrm{Na}_{2} \mathrm{~S}$ is added. For, assuming the law of mass action, the ionic concentration of the $\mathrm{Hg}$ obtained from the $\mathrm{Hg}_{2} \mathrm{~S}$ will diminish when, by introduction of further quantities of $\mathrm{Na}_{2} \mathrm{~S}$, the concentration of the $\mathrm{S}$ ions in solution is raised.

Suppose now that to a solution containing an excess of $\mathrm{Na}_{2} \mathrm{~S}$ a small quantity $2 c^{\prime \prime}$ of an acid $\mathrm{HX}$ is added. Then we shall get

$$
\begin{aligned}
& c \mathrm{Hg}_{2} \mathrm{Cl}_{2}+\left(c+c^{\prime}\right) \mathrm{Na}_{2} \mathrm{~S}+2 c^{\prime \prime} \mathrm{HX} \\
& =c \mathrm{Hg}_{2} \mathrm{~S}+\left(c^{\prime}-c^{\prime \prime}\right) \mathrm{Na}_{2} \mathrm{~S}+c^{\prime \prime} \mathrm{H}_{2} \mathrm{~S}+2 c^{\prime \prime} \mathrm{NaX}+2 c \mathrm{NaCl} \text {. }
\end{aligned}
$$

Now if we assume the coefficients of ionization of the $\mathrm{Na}_{2} \mathrm{~S}$ and the $\mathrm{H}_{2} \mathrm{~S}$ to be $\gamma$ and $\delta$ respectively, the concentration of $\mathrm{S}$ ions arising from these two substances will be $\gamma\left(c^{\prime}-c^{\prime \prime}\right)+\delta c^{\prime \prime}$; while, before the addition of the acid, the concentration of $\mathrm{S}$ ions arising from the $\mathrm{Na} \mathrm{a}_{2} \mathrm{~S}$ would exceed. $\gamma c^{\prime}$. The value of $\delta$ will in general be less than that of $\gamma$, because, in moderately dilute solution, $\mathrm{H}_{2} \mathrm{~S}$ is a very poor conductor compared with $\mathrm{Na}_{2} \mathrm{~S}$. Therefore addition of the 
Potential Differences determined by Null Solutions. 489

acid $\mathrm{HX}$ will reduce the concentration of the $\mathrm{S}$ ions in the solution containing $c \mathrm{Hg}_{2} \mathrm{~S}$, and will in consequence cause the concentration of the $\mathrm{Hg}$ ions to rise. Thus addition of the acid will tend to reduce the effect of the $\mathrm{Na}_{2} \mathrm{~S}$ and will cause the electrocapillary carve to move towards the right.

Hence, if too much $\mathrm{Na}_{2} \mathrm{~S}$ has been added, so that the maximum is to the left of the origin, it may be possible to obtain a null solution by the addition of a small quantity of an acid. Moreover, it may be of advantage experimentally to proceed in this way by overshooting the mark and then adding acid, rather than by attempting to hit it by reducing the amount of $\mathrm{Na}_{2} \mathrm{~S}$. For, as can be seen, the rate at which the curve will move towards the right will be less when a small quantity of acid is added than when an equivalent quantity of sulphide is taken away. Thus, when the acid is absent, the concentration $p_{s}$ of $\mathrm{S}$ ions, outside the $\mathrm{Hg}_{2} \mathrm{~S}$, is such that $\partial p_{s} / \partial c^{\prime}$ exceeds $\gamma$; but when the acid is added

$$
\partial p_{s} / \partial e^{\prime \prime}=-(\gamma-\delta)
$$

$\S 15$. It is not contended for the above equations that they necessarily do more than indicate the course of events. The $\mathrm{Na}_{2} \mathrm{~S}$ used probably contained traces of higher sulphides, and the chemical relations between the substances concerned are complicated. The final product of the action of $\mathrm{Na}_{2} \mathrm{~S}$ on the mercury in solution would no doubt be a double sulphide of $\mathrm{HgS}$ and $\mathrm{Na}_{2} \mathrm{~S}$, and it is worth notice with regard to this that, after the very rapid change at $.00037 n \mathrm{Na}_{2} \mathrm{~S}$, the potential of the electrode continued to decrease fairly rapidly until about $\cdot 002 n \mathrm{Na}_{2} \mathrm{~S}$ had been added. The rate of decrease fell comparatively suddenly at this point, and for subsequent additions of $\mathrm{Na}_{2} \mathrm{~S}$ (until the whole of the $\mathrm{KCl}$ was replaced) remained very small.

The concentration of mercurous ions in a solution of $\mathrm{KCl}$ standing over mercury and calomel has been estimated indirectly by Behrend and others, and from the values obtained it would appear that, if the above interpretation of our observations is correct, only a small fraction of the mercury in solution can be in the ionized condition. It is important to note, however, that the comparatively large value of the solubility of $\mathrm{Hg}_{2} \mathrm{Cl}_{2}$, to which the results of $\$ 12$ seem to lead, may on account of the influence of dissolved atmospheric oxygen be more apparent than real. It is commonly agreed that the interaction between $\mathrm{Hg}$ and a solution of a chloride, from which the existence of $\mathrm{Hg}_{2} \mathrm{Cl}_{2}$ in the solution results, occurs through the intervention of the oxygen dissolved in the latter. This interaction will 
continue (1) until the solution becomes saturated with $\mathrm{Hg}_{2} \mathrm{Cl}_{2}$, or (2) until the supply of oxygen near the electrode is used up. In the latter event, further formation of $\mathrm{Hg}_{2} \mathrm{Cl}_{2}$ would cease until, by diffusion, a fresh supply of oxygen approached the electrode. Since, however, the solubility of oxygen in $n / 10 \mathrm{KCl}$ is probably much greater than that of $\mathrm{Hg}_{2} \mathrm{Cl}_{2}$, it is probable that the interaction terminates in accordance with the first of the alternatives and before the whole of the oxygen per c.cm. near the electrode is removed. If now a small quantity of $\mathrm{Na}_{2} \mathrm{~S}$ is added to the solution it will precipitate the whole or a part of the $\mathrm{Hg}_{2} \mathrm{Cl}_{2}$ with which the solution is saturated. But the further solution of $\mathrm{Hg}_{2} \mathrm{Cl}_{2}$ will be possible by interaction between the mercury, the $\mathrm{KCl}$ in the solution and the excess of dissolved oxygen. In fact the complete removal of $\mathrm{Hg}_{2} \mathrm{Cl}_{2}$ from solution by means of $\mathrm{Na}_{2} \$$, as represented in the equations given in $\$ \$ 13,14$, will not be possible until the whole of the dissolved oxygen is used up.

From this point of view, what happens when an aerated solution of $\mathrm{KCl}$ containing $\mathrm{Na}_{2} \mathrm{~S}$ is poured upon mercury may be described, figuratively, as a competition between the salts for the oxygen and mercury in the surface layer. Since any $\mathrm{Hg}_{2} \mathrm{Cl}_{2}$ formed before the removal of the $\mathrm{Na}_{2} \mathrm{~S}$ is complete will be at once decomposed by the latter and precipitated as sulphide, the net result of this competition is that the $\mathrm{KCl}$ can only interact permanently with such oxygen as the $\mathrm{Na}_{2} \mathrm{~S}$ leaves uncombined. The eritical amount of the latter is reached when it leaves none *.

In any attempt to form a complete picture of the process, however, it would be necessary to take account of possible difference in the subsequent rates of approach of $\mathrm{Na}_{2} \mathrm{~S}$ and $\mathrm{O}$ to the surface layer, from above, by diffusion and convection. This would lead us too far from our present aim.

The exact composition of our critical $\mathrm{Na}_{2} \mathrm{~S}$ solution was uncertain, and the further study of the question presented chemical difficulties which it did not seem profitable to investigate with the materials at our disposal.

\$16. Null Solution of $\mathrm{KCl}$.-The argument developed above proved successful as a working hypothesis. An $n / 10 \mathrm{KCl}$ solution containing $\cdot 001 n \mathrm{Na}_{2} \mathrm{~S}$ was first made up, and others containing different amounts of acetic acid (suggested by Palmaer's experiments) were then obtained

* Some results of experiments still in progress in connexion with this view were indicated when the paper was read. 
Potential Differences determined by Null Solutions. 491

from it. The results of the experiments with these solutions are summarized below:-

\begin{tabular}{|c|c|c|c|c|c|c|c|c|c|}
\hline & 1. & 2. & 3. & 4. & & 5. & 6. & \multicolumn{2}{|r|}{7.} \\
\hline & $\begin{array}{l}\text { Strength } \\
\text { of acetic } \\
\text { acid. }\end{array}$ & $\begin{array}{c}\text { Max. S.T } \\
\text { (scale- } \\
\text { reading) }\end{array}$ & $\begin{array}{l}\text { E.M.F. for } \\
\text { Max. S.T. } \\
\text { (rolt.) }\end{array}$ & $\begin{array}{l}\text { Horizontal } \\
\text { distance to } \\
\frac{n}{10} \mathrm{KCl} \text { curve. }\end{array}$ & sol. & $\left|\begin{array}{l}\frac{n}{10} \mathrm{KCl} \\
\text { (volt.) }\end{array}\right|+$ & $\underset{\text { (rolt.) }}{\mid \text { sol. } \mid}+$ & sol. & $\left.\right|_{\text {(volt.) }} ^{\frac{n}{10}} \mathrm{KCl} \mid+$ \\
\hline I..... & 0 & 3682 & $-\cdot 123$ & $\cdot 661$ & & $\cdot 660$ & $-\cdot 129$ & & 564 \\
\hline II.... & $.0011 n$ & 36.81 & -051 & -622 & & .618 & -.049 & & $\check{560}$ \\
\hline III.... & $0017 n$ & $36.84 ?$ & -.020 & 588 & & $\cdot 582$ & -.018 & & .564 \\
\hline IV.... & $.0023 n$ & 36.80 & -.005 & .578 & & $\cdot 571$ & -.009 & & . \\
\hline$\nabla \ldots$ & $0028 n$ & $36 \cdot 80$ & .010 & $\cdot 568$ & & -562 & .005 & & .562 \\
\hline VI... & $\cdot 0040 n$ & $36 \cdot 80$ & .020 & .556 & & $\cdot 549$ & .016 & & $\cdot 564$ \\
\hline
\end{tabular}

$36 \cdot 80=$ Maximum S.T. for $n / 10 \mathrm{KCl}$.

The numbers representing the normality in acetic acid are only approximate. Nothing turns upon the accuracy of their determination. Some of the corresponding electrocapillary curves are shown in fig. 4.

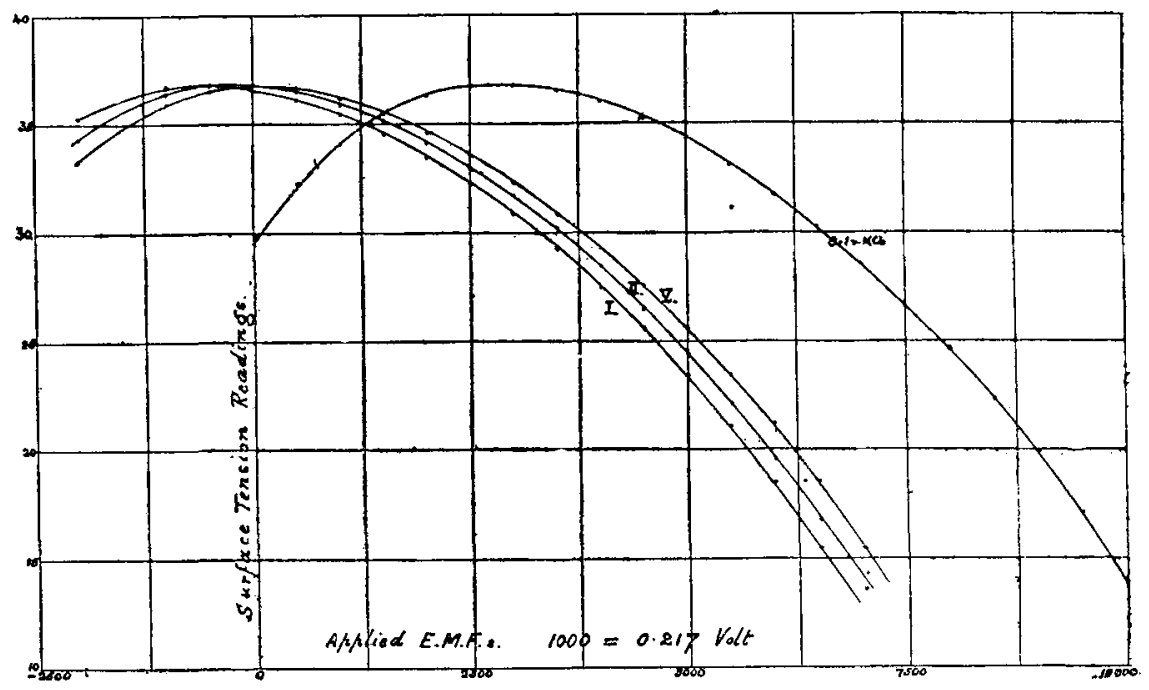

Fig: 4

The measurements are less exact than in the case of the KCN curves. Owing no doubt to the presence of small 
quantities of dissolved oxygen, the p.d. between the large $\mathrm{Hg}$ electrode and the solution sometimes changed perceptibly during the short time required to determine the electrocapillary curve. It will be seen, however, that a series of curves with practically equal maxima of surface-tension was now obtained. The null solution lies between IV. and V., and corresponds within the limits of experimental error with a solution of which the maximum of the electrocapillary curve is at the origin. Part of the difference between the numbers in columns 4 and 5 was certainly due to increase with time of the p.d. $\mathrm{Hg}$ | solution. The capillary curves were taken first and are not exactly parallel to the decinormal $\mathrm{KCl}$ curve. The distance decreases slightly towards the lower ends of the curves. The p.d. between the strongest of the solutions and the $n / 10 \mathrm{KCl}$ solution was probably less than a millivolt (cf. Palmaer, Zeit. p. Chem. l. c. 1907, p. 155).

By examination of the data for solutions IV. and V. it is seen that a null solution of the present kind, interpreted according to the assumptions of Palmaer, would give, for the p.d. $\mathrm{Hg} \mid n / 10 \mathrm{KCl}$, a value agreeing with his result. But, as will be seen, his assumption of zero p.d. between $\mathrm{Hg}$ and the null solution is not at all necessary. The only necessary conclusion is that the p.d. between the still $\mathrm{Hg}$ and the solution is the same as that between the dropping $\mathrm{Hg}$ and the solution.

From the data in the Table it is seen that, for reasons already given, the maxima being practically equal in all the solutions, the p.d. between the dropping electrode and the solution should be in every case the same. This result is probably of significance in the theory of electrocapillarity. Its truth is shown by the practical equality of all the numbers in Column 7.

§17. Effect of Oxygen upon Paschen's relation.-With respect to the data in columns 3 and $6, \S 16$, showing the fulfilment of the Paschen relation for the present series of electrolytes, it is important to state that the dropping-electrode experiments were performed in an atmosphere of hydrogen ( $c f . \S 7$, above). A piece of wide glass trubing open at both ends encircled the dropping electrode. The lower end of this tube was immersed in the electrolyte, and the upper was closed by a rubber cork in which were three holes. The drop electrode passed through the central hole: the others served for the inlet and outlet of the hydrogen respectively. 
Potential Differences determined by Null Solutions. 493

The following data are given as examples of the necessity for the exclusion of air. In one case, the maximum of the capillary curve being $+\cdot 01$ volt, a Paschen electrode against still mercury in the same solation showed -.05 volt, increasing to -.07 when the mercury jet was partially immersed. The solution quickly became cloudy and the mercury tarnished so rapidly that it fell as a dirty powder.

In another experiment the jet was surrounded by hydrogen, the water used in preparing the solution having been recently boiled to decrease the amount of dissolved air. Before complete displacement of the air by hydrogen, the Paschen electrode E.M.F. was $-\cdot 024$ volt. It fell gradually to $-\cdot 014$ volt and then remained constant. The mercury fell quite clean. Some of the solution was now withdrawn, and its electrocapillary curve was determined. The maximum lay at -.015 volt.

In a third experiment, the jet being surrounded by hydrogn, the electrode E.M.F. was - 024, agreeing with the electrocapillary maximum. Oxygen was now admitted and displaced the hydrogen. The Paschen electrode E.M.F. became $-\cdot 140$. With the jet partially immersed the E.M.F. increased to $-\cdot 240$.

Various experiments with other gases and with insulating liquids were tried, e. g., it was found that the Paschen relation was, under certain conditions, fulfilled when air was replaced by benzene; but further description of these experiments is omitted from consideration of space.

\$18. Inferences from results obtained with Null Solutions of $\mathrm{KCN}$ and of $\mathrm{KCl}$. - Summarizing the results of the two series of experiments described, it is seen that, with respect to the p.d. Hg | electrolyte as considered by Palmaer, there are two kinds of null solution. One is formed by the addition to the electrolyte of very small quantities of certain substances which leave the shape of the electrocapillary curve unaltered, with the maximum undepressed, but move it parallel to itself towards the left. This kind of null solution, interpreted in the way described by Palmaer, will give the result that the p.d. is zero at the maximum of the electrocapillary curve.

A second kind of null solution is obtained by using a different electrolyte and altering its concentration until the maximum of the capillary curve is at the origin. This kind may have a depressed maximum compared with the original electrolyte, $\mathrm{KCl}$ for example, and will in that case give a value, for the p.d. $\mathrm{Hg} \mid \mathrm{KCl}$, greater than that obtained by

Phil. Mag. S. 6. Vol. 15. No. 88. April 1908. $2 \mathrm{~L}$ 
Palmaer if the measurements are interpreted in the way he describes. If, on the other hand, the curve for the nullsolution electrolyte has a higher maximum than the corresponding curve for $\mathrm{KCl}$, then the p.d. $\mathrm{Hg} \mid \mathrm{KCl}$ found by Palmaer's method will be less than that which he gives. We have not attempted to find a null solution exactly of this last kind, although it is known that the electrocapillary maximum of a saturated $\mathrm{KOH}$ solution is near the origin and is considerably higher (Phil. Trans. l. c. p. 68) than that of concentrated $\mathrm{KCl}$.

We have, however, obtained null solutions by the addition of small quantities of $\mathrm{Na}_{2} \mathrm{~S}$ (and acetic acid) to $n / 10 \mathrm{KI}$ solution, which has a very depressed maximum, and to $n / 10 \mathrm{KOH}$ solution, which has a higher maximum than $n / 10 \mathrm{KCl}$. The results of these experiments exhibit the truth of the conclusions we have drawn.

\$19. Null Solution of KI.-The attempt to obtain a null solution from $n / 10 \mathrm{KI}$ succeeded approximately when the composition of the solution was about $\cdot 001 n \mathrm{Na}_{2} \mathrm{~S}+\cdot 099 n \mathrm{KI}$. The maximum surface-tension occurred when the applied E.M.F. was - ${ }^{\circ} 01$ volt. It was unnecessary for our purpose to obtain a nearer approximation to a null solution. The E.M.F. between a dropping electrode falling through hydrogen into this solution and a still electrode was at first imperceptible. After some time it was $\cdot 006$ volt. Mercury in this solution measured against mercury in $n / 10 \mathrm{KCl}$ gave an E.M.F. of $\cdot 793$ volt. A fresh null solution of $\mathrm{KCl}$, made up by trial for comparison, measured against $n / 10 \mathrm{KCl}$ in the same way gave $\cdot 565$ volt. The two solutions measured against each other gave $\cdot 228$ volt. The results of the measurements are tabulated below:-

\begin{tabular}{|c|c|c|c|c|c|c|}
\hline 1. & 2. & 3. & 4. & 5 & 6. & 7. \\
\hline Null Solution. & $\begin{array}{c}\text { Max.S.T. } \\
\text { (Bcale- } \\
\text { rending). }\end{array}$ & $\begin{array}{c}\text { E.M.F. for } \\
\max \text { S.T. } \\
\text { volt. }\end{array}$ & $\begin{array}{c}\text { Horizontal } \\
\text { distance to } \\
\frac{n}{10} \mathrm{KCl} \text { curve. } \\
\text { volt. }\end{array}$ & 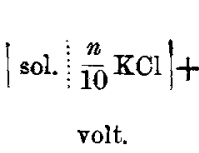 & $\mid \begin{array}{c}\mid \text { sol. } \mid+ \\
\text { volt. }\end{array}$ & $\left|\begin{array}{c:c}\operatorname{null} & \text { null } \\
\mathbf{K I} & \mathbf{K C l}\end{array}\right|+$ \\
\hline $\begin{array}{l}\frac{n}{10} \mathrm{KI}+\frac{n}{1000} \mathrm{Na}_{2} \mathrm{~S} \\
\frac{n}{10} \mathrm{KCl}+x \mathrm{Na}_{2} \mathrm{~S} \ldots\end{array}$ & $28 \cdot 85$ & $\begin{array}{l}-.01 \\
-.01\end{array}$ & $\cdot 789$ & 793 & -.01 & .228 \\
\hline
\end{tabular}


Potential Differences determined by Null Solutions. 495

These experiments show that the p.d. $\mathrm{Hg} \mid n / \mathbf{1 0} \mathrm{KCl}$ cannot be 0.57 unless, interpreting them according to Palmaer's method, the p.d. between $n / 10 \mathrm{KCl}$ and $n / 10 \mathrm{KI}$ is nearly a quarter of a volt. Such a potential-difference is impossible according to the theories at present in vogue (cf. Phil. Trans. l. c. p. 62).

\$20. Null Solution of KOH.-In attempting to obtain a null solution from $n / 10 \mathrm{KOH}$ it was found that the addition of $\mathrm{Na}_{2} \mathrm{~S}(\cdot 001 n$ to $\cdot 002 n)$ produced a gradual shift of the maximum to the left which continued over a long time. A solution with the maximum at the origin could not be obtained conveniently with $\mathrm{Na}_{2} \mathrm{~S}$ alone on account of this time effect It was found however that if, after the solution had stood for some time over the mercury, dilute acetic acid was added drop by drop and the solution stirred, the maximum could be brought from the left to zero and the time effect was now negligible. The results of the experiments with this null solution are given below :-

\begin{tabular}{|c|c|c|c|c|c|}
\hline 1. & 2. & 3. & 4. & 5. & 6. \\
\hline $\begin{array}{c}\text { Null } \\
\text { Solution. }\end{array}$ & $\begin{array}{l}\text { Max. } \mathbf{S . T} \text {. } \\
\text { (scale- } \\
\text { reading) }\end{array}$ & $\begin{array}{c}\text { E.M.F. for } \\
\max . \text { S.T. } \\
\text { volt. }\end{array}$ & $\begin{array}{c}\text { Horizontal } \\
\text { distance to } \\
n \\
\overline{10} \mathrm{KCl} \text { curve. } \\
\text { volt. }\end{array}$ & $\begin{array}{l:l}\substack{\text { null. } \\
\text { sol. }} & \frac{n}{10} \mathrm{KO} \mid+ \\
& \text { volt. }\end{array}$ & 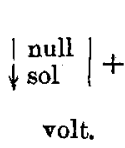 \\
\hline $\begin{array}{l}\frac{n}{10} \mathrm{KOH} \\
+\mathrm{Na}_{2} \mathrm{~S} \\
+\mathrm{HC}_{2} \mathrm{H}_{3} \mathrm{O}_{2}\end{array}$ & $30 \cdot 61$ & $+\cdot 01$ & 515 & .509 & .008 \\
\hline
\end{tabular}

In considering the value 0.509 volt in column 5 it has to be remembered that there is now an appreciable p.d. between the solutions. Its value calculated in the usual way is $n / 10 \mathrm{KOH} \mid n / 10 \mathrm{KCl}=\cdot 016$ volt at $20^{\circ} \mathrm{C}$.; and consequently we now obtain, according to Palmaer's method, $\mathrm{Hg} \mid n / 10 \mathrm{KCl}=525$ volt. But, according to the interpretation we have offered, this result signifies only that the potential reckoned from the solution to mercury at the maximum is about $\cdot 04$ volt less in the case of $n / 10 \mathrm{KOH}$ than in that of $n / 10 \mathrm{KCl}$. A result which, as before, is in agreement with the forms and relative positions of the electrocapillary curves. 


\section{Potential Differences determined by Null Solutions.}

The electrocapillary curves for the null solutions of $\mathrm{KI}$ and of $\mathrm{KOH}$ are shown in fig. 5.

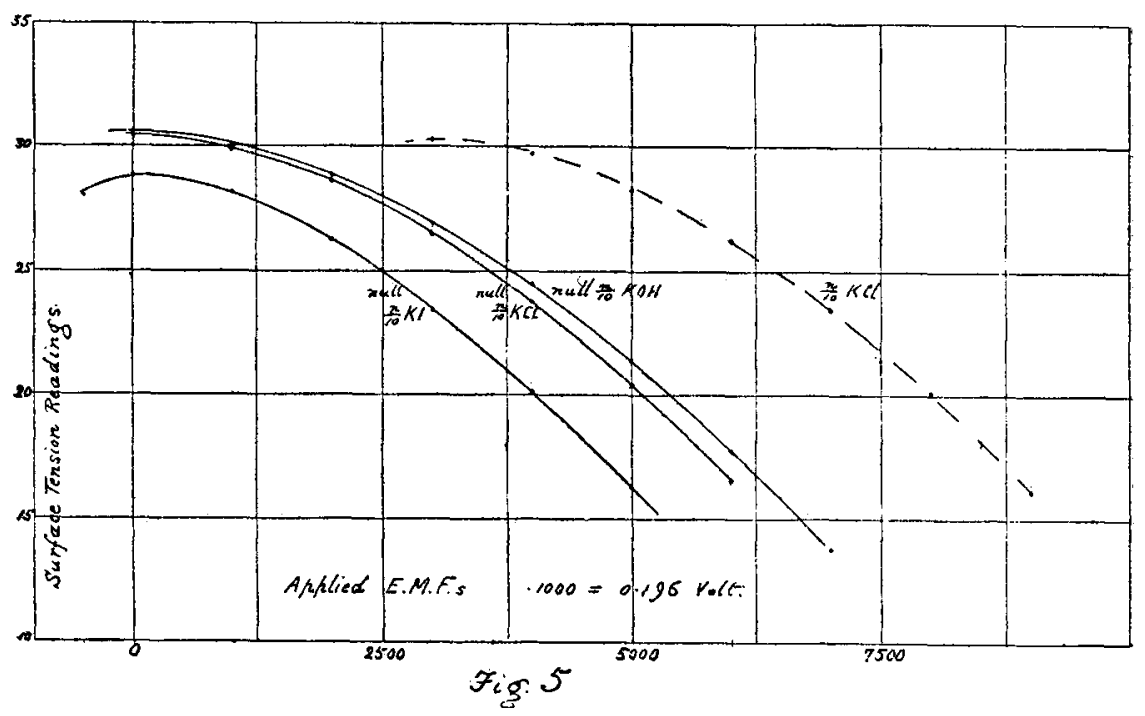

The results of our experiments may be summarized as follows :-

\$21. Summary of Conclusions.

1. The potential-differences between different null solutions and mercury are not the same. This is proved, allowing for the contact p.d. between electrolytes, by measuring each p.d. against the p.d. $\mathrm{Hg} \mid \mathrm{KCl}$, and also by measuring one null solution against another. The result is also deducible from the electrocapillary curves alone, without introduction of the question of the p.d. between electrolytes.

2. If the null-solution potential-differences are assumed to be zero, the values obtained for the p.d. $\mathrm{Hg} \mid n / 10 \mathrm{KCl}$ vary from about 0.53 volt to 0.79 volt. Assuming that the p.d. at the electrocapillary maximum is most likely to be zero when the maximum is undepressed, it is probable that the p.d. $\mathrm{Hg} \mid n / 10 \mathrm{KCl}$ does not exceed 0.53 volt.

3. The polarizing E.M.F. required to produce the maximum surface-tension between mercury and a given electrolyte has been proved by Paschen to be equal, in many cases, to the E.M.F. of the corresponding dropping-electrode circuit. This relation is shown to be true in four particular cases in which each E.M.F. is equal to zero. It is also shown that 
Lateral Vibration of Bars supported at Two Points. 497 in none of these cases is the p.d. $\mathrm{Hg}$ | electrolyte necessarily zero.

4. It is shown that the Paschen relation immediately fails when the chemical action at the drop-electrode due to atmospheric oxygen becomes appreciable.

5. The Paschen E.M.F. between mercury and a solution of $\mathrm{KCl}$ remains unchanged on the addition to the solution of small quantities of $\mathrm{Na}_{2} \mathrm{~S}$, although the natural p.d. between mercury and the $\mathrm{KCl}$ solution is thereby altered by more than half a volt.

6. A critical percentage of $\mathrm{Na}_{2} \mathrm{~S}$ was found for which the natural p.d. just mentioned altered with extreme rapidity as in the cases studied by Behrend, in which he observed the variation of the E.M.F., $\mathrm{Hg}\left|\mathrm{Hg}_{2}\left(\mathrm{NO}_{3}\right)_{2}\right| \mathrm{Hg}$, produced by the gradual addition of $\mathrm{KCl}$ or $\mathrm{KBr}$ at one electrode. In the present case the change in the p.d. $\mathrm{Hg}$ | electrolyte was deduced directly from the electrocapillary curves.

XLVI. On the Lateral Vibration of Bars supported at Two Points with One End overhanging. By JOHN MoRrow, M.Sc., D.Eng.; Lecturer in Engineering, Armstrong College (University of Durham)*

WHEN a bar is carried on two supports and has one end overhanging by an amount $c$, as shown in the figure,

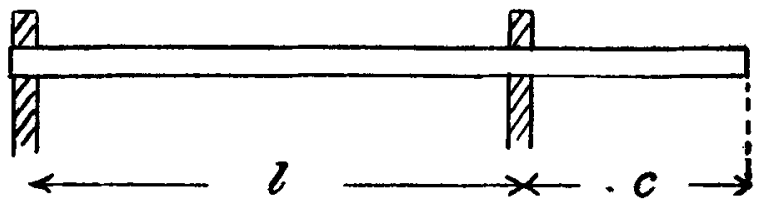

its natural period of vibration is to be determined from the equation

$(\cosh m l \sin m l-\sinh m l \cos m l)(\cosh m c \sin m c-\sinh m c \cos m c)$ in which $-2 \sinh m l \sin m l(1+\cosh m c \cos m c)=0$,

$m=(2 \pi \mathrm{N})^{\frac{1}{2}}(\rho \omega / \mathrm{EI})^{\frac{1}{4}}$;

$\mathrm{E}=$ Young's Modulus for the material ;

$I=$ the moment of inertia of the section about an axis perpendicular to the plane of bending;

$\omega=$ sectional area of bar (assumed uniform);

$\rho=$ density of material ;

$\mathrm{N}=$ frequency of natural vibrations.

* Communicated by the Physical Society : read November 8, 1907. 